\title{
The Atlantic Diet - Origin and features
}

\author{
Manuela Vaz Velho ${ }^{a^{*}}$, Rita Pinheiro $^{a}$, And Ana Sofia Rodrigues ${ }^{b}$

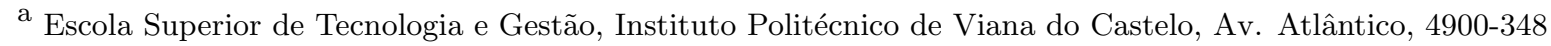 \\ Viana do Castelo, Portugal \\ b Escola Superior Agrária, Instituto Politécnico de Viana do Castelo, Refóios, 4990-706 Ponte de Lima, Portugal \\ ${ }^{*}$ Corresponding author \\ mvazvelho@estg.ipvc.pt \\ TEL: $+351-258819700$ \\ FAX: +351-258827636
}

Received: 6 April 2015; Published online: 18 April 2016

\begin{abstract}
Despite globalization there still are food patterns which are clearly differentiated from one region to another in Europe and elsewhere. In this study the Atlantic Diet is considered as the traditional diet in Portugal and Galicia, a region in northwest Spain.

This paper aims to contribute to a better understanding of the Atlantic Diet food pattern in order to fully exploit the potential of this Atlantic gastronomical heritage.

The background of the Atlantic Diet concept, the characterization of Atlantic Diet foods and a compilation of scientific findings related to the consumption of these foods are covered.

A brief description of the Mediterranean Diet, the primitive pattern and the updated Mediterranean pyramid are also included in order to aid understanding of the globalization of this previously local health food pattern.

Final remarks and suggestions for further studies are made.
\end{abstract}

Keywords: Atlantic Diet; Food patterns

\section{Introduction}

The Atlantic Diet concept originated some years ago when the Instituto Politécnico de Viana do Castelo (IPVC), University of Santiago de Compostela, Spanish Nutrition Foundation (FEN) and Galician Association for the study of the Atlantic Diet (ASGAEDA) joined forces with the objective of placing the Atlantic Diet as a worldwide reference for a healthy diet. As a result of discussions between scientists from the Spanish and Portuguese Atlantic regions, the European Center for the Atlantic Diet (CEDA) was founded in 2003 in Portugal. Subsequently the "Atlantic Diet Foundation" was created in 2007 in Galicia, Spain by the University of Santiago de Compostela.

Copyright (C)2016 ISEKI-Food Association (IFA)
In 2006 these institutions and organizations committed to the Atlantic Diet signed the "Baione Declaration on the Atlantic Diet" with the aim of developing a strategy for the promotion and maintenance of the Atlantic Diet at different levels, and having the following objectives:

- The promotion of the Atlantic Diet as a source of health and pleasure;

- The promotion of research, development and innovation on the Atlantic Diet, with respect to health in the area of fisheries, aquaculture, agriculture, livestock, viticulture and natural resources;

- The involvement of the food industry, tourism and catering sectors to develop and

10.7455/ijfs/5.1.2016.a10 
The Atlantic Diet | 107

apply the main elements of the Atlantic Diet within principal and supplementary foods, through both traditional and innovative cooking preparations and supply for consumption at home and outside it;

- The involvement of the educational sector at various levels to educate consumers about the cultural heritage of the Atlantic Diet;

- Ensure that public and private institutions recognize the values of the Atlantic diet, lifestyle and the accompanying environmental commitments, and are committed to their protection and promotion as a functional diet;

- Assess the potential environmental impact in its broadest sense (urbanization, transportation, environmental pollution, etc.) of maintaining the values of the Atlantic Diet.

For the above purposes, two International congresses, one seminar and three international meetings, specifically dedicated to the Atlantic Diet, were organized.

The $1^{\text {st }}$ International Congress on the Atlantic Diet, organized by CEDA, took place in Viana do Castelo, Portugal from 17 to 19 July, 2003. Two years later a seminar entitled: "Atlantic Diet, Benefits for your Health and Well-Being" took place in Santiago de Compostela, Spain from 29 to 30 April, 2004. The $2^{\text {nd }}$ International Congress on the Atlantic Diet, organized by University of Santiago de Compostela, took place in Baiona, Spain, from 16 to 18 November, 2006. Three international meetings, organized by the Fundación Española de la Nutrición (2003, 2005 and 2008) were also focused on the Atlantic Diet. Furthermore, in many other scientific and technical events, not restricted to the Atlantic Diet, the subject of the Atlantic Diet was also incorporated, for example:

The XVII Congresso de Gastronomia do Minho and V Congresso Luso-Galaico, with a Session II "A Dieta Atlântica na Euro região GalizaNorte de Portugal", took place in Vila Nova de Cerveira, Portugal, 26-29 April 2007; The $1^{\text {st }}$ International Congress of Gastronomy and Wines Portugal, with a session III "The gastronomy and wines in Europe - Atlantic Diet", took place in Matosinhos, Portugal, 24-26 November 2011; and the Atlantic Stakeholder Platform Conference, with its Session A4 "Atlantic Tourism Atlantic Diet: Why include food from the sea in your diet", took place in Porto, Portugal, 20 January 2015.

\section{Atlantic Diet Features}

Since 2000 there have been many attempts to establish the Atlantic Diet features. At the creation of the European Center for Atlantic Diet (CEDA), the Instituto Politécnico de Viana do Castelo ordered a study to compile general features of the Atlantic Diet. In this first study (Leslie, 2000) the author chose countries which were representative of three regions of Europe, with different types of climates, geographic environments and lifestyles: Atlantic, Mediterranean and Central European countries. The countries considered were as follows:

- Atlantic region: Portugal, Spain, France, Ireland, United Kingdom, Belgium, Netherlands, Denmark, Norway and Iceland. The results concerning Spain and France have to be taken with caution as they also belong to Mediterranean countries;

- Mediterranean countries: Italy and Greece;

- Central European countries: Germany, Czech Republic, Poland, Austria and Switzerland.

The precise characterization of the Atlantic Diet was not the objective of this study but rather to provide an overview of the different dietary intake patterns found in the European Atlantic countries. This covered eating habits, the main ingredients used and the typical dishes found in each country (Table 1), as well as a comparison between diets in Central, Mediterranean and the Atlantic regions of Europe which allowed the identification of some general features of the Atlantic Diet.

The strategic plan for the European Center for Atlantic Diet (CEDA) was developed by Sociedade Portuguesa de Inovação, S.A. (SPI, 2001). Based on the 1999 version of the nutrition database of the Food and Agriculture Or- 
ganization of the United Nations, a few features were compiled that were still valid in 2011 and are therefore presented in this chapter.

The consumption of seafood (including fish) is higher in the Atlantic countries than in the Central European countries. Countries close to the sea consume more sea products than landlocked countries because of the easy availability of fish. For the two Mediterranean countries, their consumption of fish is more or less the same as in Denmark, Netherlands, Belgium, United Kingdom and France. The northern and southern Atlantic countries differentiate themselves from all the other countries by their very high consumption of fish, although Iceland has a fish consumption significantly higher than other Atlantic countries. The limited agricultural production in Iceland, due to its soil and climate characteristics (Jóhannesson, 2010) together with the easy availability of fish might justify this high consumption of fish products. After Iceland (annual per capita fish supply of $90 \mathrm{~kg}$ ), comes the southern and northern countries of the Atlantic: Portugal, Norway, Spain, France and Denmark with $56.8,53.4,42.4$ and $34.6 \mathrm{~kg}$, respectively (FAOSTAT Food balances, 2011). The data refers to per capita fish supply and not per capita fish consumption as the former includes losses through distribution and food preparation.

It can be observed that the countries in the center of Europe have the largest difference in the consumption of meat and fish; they eat much more meat than fish. Their physical environment is more favorable to the breeding of livestock than to access to fish.

A second observation is that the Atlantic countries in the central region of the Atlantic Corridor (Spain, France, United Kingdom, Belgium, Netherlands and Denmark) have more or less the same meat/fish ratio than the countries representing the Mediterranean countries. The three extremities of Atlantic European countries (Portugal, Norway and Iceland) have a different ratio from the other countries. For Iceland, as mentioned before, fish is more important in the diet than meat. Concerning Portugal and Norway, fish is almost eaten in the same quantity as meat. There is a large difference in the consumption of potatoes and vegetables between Mediterranean and Atlantic countries. In Atlantic countries, people eat in general more potatoes and fewer vegetables than in Mediterranean countries. This follows the assumption that potatoes are one of the characteristics of an Atlantic Diet. Comparing the Central region of Europe and the Atlantic region, the difference is not so marked.

Nevertheless, it can be noticed that southern Atlantic countries are larger consumers of vegetables than Central regions. There is a gradient 'South North' for the consumption of vegetables: countries that are located in the South region eat more vegetables than in the North. The natural conditions, due to the sunnier climate of the southern Atlantic countries, favor the cultivation of vegetables.

There are no major differences in the consumption of milk among the three regions: Atlantic, Mediterranean and Central region of Europe but Norway can be distinguished by its higher consumption of milk. This fact is not a surprise upon considering the nutritional characteristics of this product and the European Agricultural Policies. Europe has an excess of milk production and its consumption has been promoted throughout the European Union. Types of milk, other than cow milk, can be more specific to some regions; however the consumption of other types of milk is very low when compared with cow milk.

The European Atlantic region includes Portugal, some regions of Spain, some regions of France, Ireland, United Kingdom, Belgium, Netherlands, Denmark, Norway and Iceland, which is not an EU country. However, geographical location is not enough to determine a common food pattern as diet is influenced by many other factors, including income, culture, religion and lifestyle. In the last century, the globalization of diets, sometimes for health reasons, sometimes for its convenience, and other factors, such as world wars, resulted in dramatic changes to the consumption of traditional foods in European Atlantic regions. There is evidence of the impact of the First World War on food consumption and nutrition in Britain (Gazeley \& Newell, 2013). In Portugal and Galicia, traditional foods, many of which have a Celtic influence (for example, broths with meat and cabbage) are still eaten every week at home and can be found in the majority of restaurants. Whereas the Irish colcannon and the Welsh cawl traditional dishes, with 
The Atlantic Diet | 109

meat and cabbage, are only consumed on festive days or more recently in a few new traditional restaurants. Scientists from Galicia and Portugal, at the time of formation of CEDA in 2003, considered that the Atlantic Diet food pattern is still "alive" in those regions and the Atlantic Diet was defined as the traditional diet of Portugal and Galicia.

A relevant book entitled "La Dieta Atlántica, el pescado y las algas - Su importancia en el neurodesarrollo y la función cerebral"

parenciteTojo2009 was edited by the University of Santiago de Compostela in 2009. The authors compiled anthropological and historical information about the nutritional characteristics of diets from prehistory to recent days, together with information about food patterns in the Northwest of Spain and in the Spanish Mediterranean border regions, which enabled comparisons to be made. They defended the role of the Atlantic Diet as a health counterpoint to the recent Western Diet.

The type of foods associated with the traditional Atlantic Diet of Galicia identified by Tojo and Leis (2009) are as follows:

High intake of seasonal foods, locally fresh and minimally processed; High intake of vegetables, fruits, potatoes, bread and cereals, chestnut, whole nuts, legumes and honey; Use of olive oil for seasoning and olive oil and pork lard to cook; High consumption of fish, mollusks and crustaceans; Moderate consumption of milk and cheese; Moderate consumption of meat (cow and pork); Moderate consumption of eggs; Moderate consumption of wine usually with meals; Consumption of sauces with a healthy fat profile; Moderate consumption of simple sugars, desserts based on cereals, dried fruits and eggs; High intake of mineral water, with a healthy mineral profile; Cooking methods mainly by boiling, stewing, roasting and grilling. Authors stated these foods will ensure an abundant intake of complex sugars and fiber; an abundant intake of PUFAs (LCPUFAs omega-3 with a good ratio of omega6/omega3, oleic acid and linoleic CLA; adequate vitamin and mineral intake; and abundant intake of functional food components (such as antioxidants, sterols, flavonoids, carotenoids, lycopene and indols).

The Atlantic Diet pyramid built by Tojo and Leis
(2009) (Figure 1) is placed in all refectories of the University of Santiago de Compostela. The types of food and cooking methods used for everyday student meals at the University of Santiago de Compostela are based on it (Tojo, 2008).

No major differences were found in Portuguese and Galician food patterns in 2000 by Leslie (2000) but a feature of the Portuguese diet should be emphasized - the daily intake of vegetable soup with Brassica species and the presence of rice in most of the meals already mentioned in Table 1. It is important to mention that under the designation "Vegetables" of FAOSTAT food balances (2011), tomatoes and onions are discriminated but the remaining vegetables are placed together as an item named "Other vegetables" of which Portugal presents the higher supply of $113.9 \mathrm{~kg}$ per capita compared to the other Atlantic countries. However, it can be assumed that Brassica species (cabbage) constitute a significant proportion of this supply as it is the second most consumed vegetable after potatoes in Portugal (Gevers et al., 1998). The consumption of different vegetables in 13 European countries for 1998 is shown in Table 2.

It is curious, despite the international reknown of Spanish paella or Italian risotto, that Portugal has a higher rice supply per capita in Europe- $16.3 \mathrm{~kg} /$ year whereas Spain and Italy have 9.4 and $5.2 \mathrm{~kg} /$ per capita/year respectively. The European average rice supply is only 4.9 $\mathrm{kg}$ per capita/year (FAOSTAT food balances, 2011). In Portugal, rice and potatoes are consumed daily within main meals. The most traditional food dish throughout Portugal is Cozido à Portuguesa, similar to Galician Cozido and containing various meats, boiled potatoes and cabbage, but is also accompanied with rice. Another very traditional dish is Feijoada à Portuguesa, a pork meat stew with beans, which is also accompanied with rice and furthermore, in the north of Portugal this dish also contains cabbage. Finally, the best known Portuguese dish that is present in all Portuguese houses on Christmas Eve, the Bacalhau Cozido com todos, contains boiled dry salted cod with potatoes and cabbage, and fresh garlic and olive oil to season it. 
$110 \mid$ Vaz Velho et al.

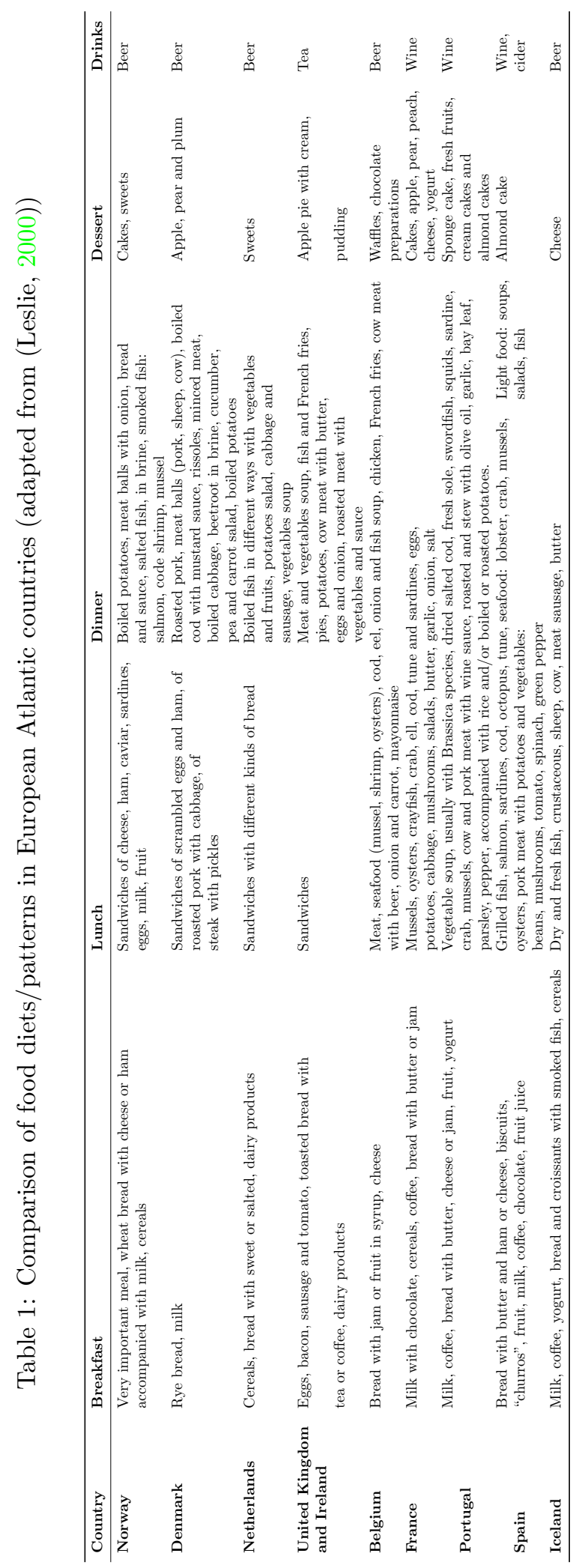

IJFS | April 2016 | Volume 5 | pages 106-119 
The Atlantic Diet | 111

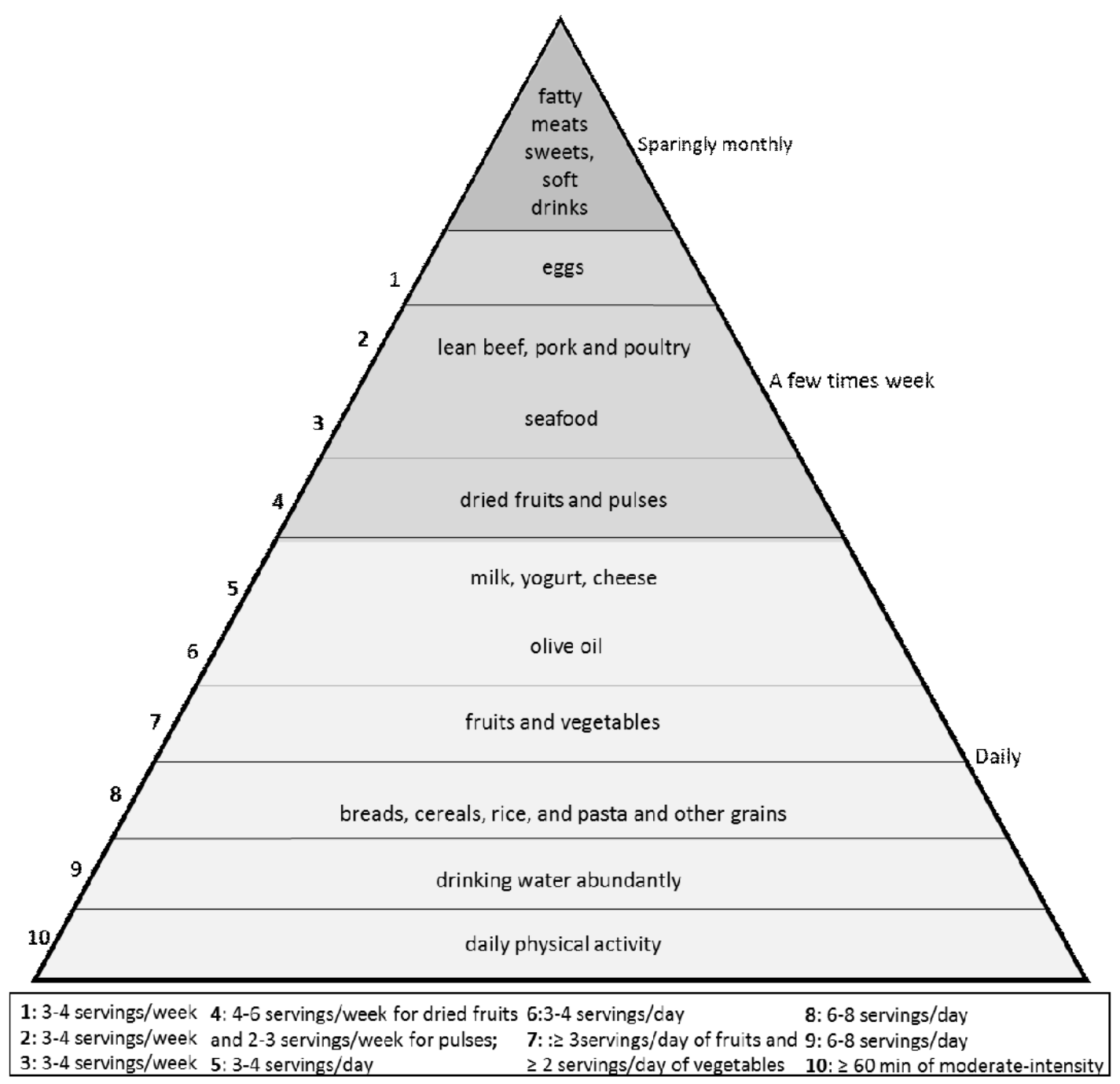

Figure 1: Atlantic Diet Pyramid (according to Tojo and Leis (2009), and translated from Spanish) 
Table 2: Consumption of vegetables in 13 European countries (g.capita-1.day-1) from Gevers et al. (1998)

\begin{tabular}{lrrrrrrrrrrrrrr}
\hline Vegetable item & A & B & DK & GB & FIN & F & D & I & NL & P & E & S & CH & Average \\
\hline Potatoes & 133 & 250 & 156 & 126 & 132 & 54 & 198 & 55 & 233 & 372 & 145 & 177 & 118 & $\mathbf{1 3 8 . 0}$ \\
Tomato & 26 & 37 & 44 & 18 & 29 & 20 & 40 & 99 & 15 & 26 & 51 & 21 & 25 & $\mathbf{4 1 . 5}$ \\
Lettuce & 12 & 21 & 7 & 17 & 3 & 6 & 8 & 34 & 8 & 10 & 24 & 8 & 23 & $\mathbf{1 5 . 7}$ \\
Onion & 18 & 23 & 27 & - & - & 4 & 19 & 9 & 10 & 36 & 17 & 15 & 13 & $\mathbf{1 4 . 0}$ \\
Cabbage & 16 & - & 14 & - & 7 & - & 10 & 2 & 15 & 114 & 7 & 16 & 13 & $\mathbf{1 3 . 0}$ \\
Carrots & 8 & 20 & 31 & 10 & 22 & 13 & 10 & 7 & 16 & 18 & 10 & 18 & 25 & $\mathbf{1 1 . 7}$ \\
Beans & 6 & 13 & - & 3 & - & 10 & 6 & 14 & 5 & 27 & 13 & - & 5 & $\mathbf{9 . 2}$ \\
Cucumber & 14 & 5 & 13 & - & 16 & - & 12 & 2 & 16 & 2 & - & 10 & 5 & $\mathbf{8 . 5}$ \\
Pimento & 8 & 3 & - & - & - & - & - & 8 & 6 & 7 & 11 & 4 & 4 & $\mathbf{7 . 8}$ \\
Cauliflower & 5 & - & 9 & - & 2 & 6 & 9 & 2 & 14 & 2 & - & - & 6 & $\mathbf{6 . 3}$ \\
\hline
\end{tabular}

A: Austrian; B: Belgian; DK: Denmark; GB: Great Britain; FIN: Finland; F: France; D: Germany; I: Italy; NL: Netherlands; P: Portugal; E: Spain; S: Sweden; CH: Switzerland.

* Brassica oleracea

\section{Atlantic Diet and Health}

The term diet refers to a person's pattern of eating and drinking. Diet is influenced by many factors, including income, culture, religion, geographic location, and lifestyle.

Most of the so-called western countries have dietary guidelines. One of the most reported is the USA Dietary Guidelines, first published in 1980, and reviewed, updated and released by U.S. Department of Health and Human Services (HHS) and the U.S. Department of Agriculture (USDA) every five years. These Dietary Guidelines contain the latest, science-based nutritional and dietary guidance for the general public. They are the foundation for federal nutrition education and promotion programs, as well as the basis for the federal food assistance programs. The Scientific Report of the 2015 Dietary Guidelines Advisory Committee (Advisory Report) was submitted to the Secretaries of the U.S. Department of Health and Human Services (HHS) and the U.S. Department of Agriculture (USDA) in February 2015 and underwent a Public Consultation Period until May 8 (http://www.health. gov/dietaryguidelines/2015-scientific-report/ accessed on 2 April 2015).

A balanced diet contains food from several food groups and supplies the body with the energy and essential nutrients it needs (United States Department of Agriculture (USDA) Center for Nutrition Policy and Promotion (http://fnic. nal.usda.gov/dietary-guidance), accessed on 31
March 2015).

The European Food Safety Authority (EFSA) provides up-to-date and comprehensive scientific advice to support EU policy makers in their decision making process in the field of nutrition for the setting of diet-related public health targets and the development of consumer information and educational programmes on healthy diets. In March 2010, EFSA's Panel on Dietetic Products, Nutrition and Allergies established dietary reference values for the intake of carbohydrates, dietary fibre, fats and water (http://www.efsa. europa.eu/en/topics/topic/drv.htm accessed on 1 April 2015).

Epidemiological, experimental and clinical trial evidence have demonstrated over the last 50 years a relationship between diet, nutrients and blood lipid levels (Van Horn et al., 2008).

Nowadays, foods consumed worldwide include ice cream, candy, pastries, potato chips or other salted and fatty snacks (Haber, 1997). These fast food and other processed convenience foods, together with more meat and other animal products, fewer fresh fruits and vegetables, are considered to be responsible for burgeoning rates of heart disease, obesity, diabetes, and other chronic diseases.

One of the key concerns of nutritionists is to establish relationships between the type of diet consumed by the population and the existence of non-transmissible chronic diseases. Nutritional interventions that have been applied worldwide are multiple and involve different aspects that 
The Atlantic Diet | 113

contribute to improved food and nutrition patterns worldwide (Rand, Windham, Wyse, \& Young, 1987; Araya, 1997). Arising from a meeting of representatives of the Federation of European Nutrition Foundation no identification of bad or good food should be indicated to consumers in a regular balanced diet (La Place, 2004). A daily diet is not only food but also taste and pleasure.

Epidemiological studies point out that about $75 \%$ of human cancers are related to extrinsic factors, the most important smoking and diet (Fahey \& Talalay, 1995). Prevention of cancer by naturally occurring substances in foods is an area of growing interest to the scientific community.

Several scientific studies have already demonstrated the health benefits of Atlantic Diet food components. In particular, fish consumption and other seafood, vegetables, low alcohol content beverages, and the Atlantic Diet's preventive value in heart disease, metabolic and some cancers. Vitamin B, omega 3 fatty acids and iodine are three components of the Atlantic Diet which may bring health benefit to consumers residing in the Atlantic area.

The association between fish consumption and risk of cardiovascular disease (CVD) has been extensively studied. Epidemiological and clinical trial evidence suggests that omega-3 polyunsaturated fatty acids (PUFAs) might have a significant role in the prevention of coronary heart disease. Dietary sources of omega-3 PUFA include fish oils rich in eicosapentaenoic acid and docosahexaenoic acid along with plants rich in alpha-linolenic acid. Evidence suggests that increased consumption of n-3 FAs from fish or fishoil supplements, but not of alpha-linolenic acid, reduces the rates of all-cause mortality, cardiac and sudden death, and possibly stroke (Wang et al., 2006).

Randomized clinical trials (RCTs) with fish oils (eicosapentaenoic acid and docosahexaenoic acid) and alpha-linolenic acid have demonstrated reductions in risk that compare favorably with those seen in landmark secondary prevention trials with lipid-lowering drugs. The results of prospective cohort studies indicate that consuming fish or fish oil containing the n-3 fatty acids eicosapentaenoic acid (EPA) and docosa- hexaenoic acid (DHA) is associated with decreased cardiovascular death, whereas consumption of the vegetable oil-derived n-3 fatty acid a-linolenic acid is not as effective. RCTs in the context of secondary prevention also indicate that the consumption of EPA plus DHA is protective at doses $<1 \mathrm{~g} / \mathrm{d}$. The therapeutic effect appears to be due to suppression of fatal arrhythmias rather than stabilization of atherosclerotic plaques. At doses $>3 \mathrm{~g} / \mathrm{d}$, EPA plus DHA can improve cardiovascular disease risk factors, including decreasing plasma triacylglycerol's, blood pressure, platelet aggregation, and inflammation, while improving vascular reactivity. Mainly on the basis of the results of RCTs, the American Heart Association recommends that everyone eat oily fish twice per week and that those with coronary heart disease eat 1 $\mathrm{g} / \mathrm{d}$ of EPA plus DHA from oily fish or supplements (Breslow, 2006).

There is little doubt that omega-3 long-chain polyunsaturated fatty acids (n-3 LCPUFAs) in fish are the key nutrients responsible for the benefits and are important for CVD prevention. Although fish is valued as a source of these fatty acids, it also provides other nutrients that may have cardioprotective effects. It is likely that the beneficial effects of fish consumption on the risk of CVD are the synergistic effects among nutrients in fish, and the integrative effects of fish consumption may reflect the interactions of nutrients and contaminants in fish (He, 2009). Shell fish species such as shrimps are rich in omega-3s and low in mercury (Smith \& Guentzel, 2010).

Regular fish consumption before the age of 1 appears to be associated with a reduced risk of allergic disease and sensitization to food and inhalant allergens during the first 4 years of life (Kull, Bergstrom, Lilja, Pershagen, \& Wickman, 2006).

A study using unsaturated fat-enriched diets with virgin olive, sun-flower and fish oil enhances hepatic antioxidant defense system; with the virgin olive and fish oil diet providing the best results (Aguilera, Mesa, Ramirez-Tortosa, Quiles, \& Gil, 2003).

A nationwide case-control study in Norway with 545 cases of childhood-onset type 1 diabetes and 1668 population control subjects concluded that the use of cod liver oil during the first year of 
life is associated with lower risk of childhoodonset type 1 diabetes (Stene, Joner, \& Norwegian Childhood Diabet Study G., 2003).

Data compiled on the relationship between diet and incidence of certain diseases concluded that a diet rich in fruit and vegetables is strongly associated with a lower risk of contracting degenerative diseases, including cardiovascular disease, brain dysfunction and cataracts, and proliferative diseases such as neoplasms (cancer) (Negri, La Vecchia, Franceschi, D' Avanzo, \& Parazzini, 1991; Steinmetz \& Potter, 1991; Block, Patterson, \& Subar, 1992; Verhoeven, Godbohm, van Poppel, Verhagen, \& van den Brandt, 1996; Gold, T.H., \& Ames, 1997; Ames \& Gold, 1998).

The health benefits of onion intake, a major food component of the Atlantic Diet, were reported by several authors (Kumari, Mathew, \& Augusti, 1995; Goldman, Kopelberg, Debaene, \& Schwartz, 1996; Teyssier et al., 2001; Griffiths, Trueman, Crowther, Thomas, \& Smith, 2002). The annual consumption of onions in Portugal was estimated at $13.8 \mathrm{~kg}$ per capita in 2011 (FAOSTAT food balances, 2011) and it is the third most consumed vegetable after potatoes and Brassica species.

Regional varieties of onion from the Northwest of Portugal were studied. Results indicate that the red variety has higher nutritional value (minerals and protein) and higher potential health benefits related to the presence of antioxidant compounds (Rodrigues et al., 2003).

A broad array of healthy properties have been attributed to Brassica species in recent years such as anticarcinogenic, protective actions against cardiovascular diseases and ageing processes, prenatal pathologies and cataracts. These benefits have been related to their high content in health-promoting phytochemicals namely glucosinolates (and their hydrolysis products, isothiocianates), phenolic compounds (hydroxycinamic acids and flavonoids), carotenoids, vitamins (ascorbic acid (AA), tocopherol, and folic acid) and minerals (Dominguez-Perles, Mena, Garcia-Viguera, \& Moreno, 2014).

The low incidence of coronary heart disease associated with moderate consumption of red wine and other alcoholic drinks have been reported (Renaud \& Delorgeril, 1992). In a review study, Bertelli (2007) reported that white wine is given less importance than red wine as it contains lower quantities of polyphenols. However, the same study underlined several other epidemiological surveys showing that wine "colour" was not found to have different effects with respect to coronary artery diseases, modulation of the release of plasma interleukin-6 and platelet function. Furthermore, both white and red wine improved the LDL/HDL cholesterol ratio and enhanced the LDL clearance rate from blood. Wine, red or white, is drunk at meals in the Atlantic Diet region.

Based on a case control study $(n=820)$ of patients hospitalized with acute myocardial infarction (AMI), adherence to the Southern European Atlantic Diet (SEAD) was associated with lower odds of nonfatal AMI (Oliveira, Lopes, \& Rodriguez-Artalejo, 2010). The authors concluded that some but not all food components of the SEAD may contribute to the very low coronary mortality in northern Portugal and Galicia. As far as we know this was the first epidemiological study examining the association between adherence to the Atlantic Diet and the occurrence of non-fatal acute myocardial infarction in Portugal. A cross-sectional study from the same authors and Spanish authors (Guallar-Castillon, Oliveira, Lopes, LopezGarcia, \& Rodriguez-Artalejo, 2013) was conducted in 2008-2010 among 10,231 individuals representative of the population aged 18 years and older in Spain. Diet was assessed with a validated computerized diet history. SEAD adherence was measured with an index including 9 food components (fresh fish, cod, red meat and pork products, dairy products, legumes and vegetables, vegetable soup, potatoes, whole-grain bread, and wine), which ranged from 0 (lowest adherence) to 9 (highest adherence). This study identified possible mediators of the effect of SEAD on myocardial infarction, because SEAD was found to be associated with a lower concentration of markers of inflammation and with reduced triglycerides, insulin, insulin resistance and systolic blood pressure.

Several other studies have pointed out the benefits of food components typical of the Atlantic Diet but not grouped as a meal nor aggregated under the concept of an Atlantic Diet Food pattern. 
The Atlantic Diet | 115

There is a continuous move from dietary traditions which are local, low in technological input and based on empiricism to diets that are global, high in technological input and science based. Over the last century societies have the ability to improve their diet based on a better scientific understanding of the health benefits of such diets but innovations are often not achieved due to commercial considerations. This will require that all sectors of the food industry to work towards healthy and economically affordable diets. In addition, there is a continuing demand by consumers to ascertain that traditional foods are not only healthy but also convenient and easy to prepare (Heinrich \& Prieto, 2008).

On current evidence the concept of the 'Atlantic Diet' appears to be as well founded as the concept of the 'Mediterranean Diet', but the major challenge is to define whether there is a traditional Atlantic Diet as healthy as the Mediterranean Diet when consumed as part of a healthy lifestyle (Lindsay, 2003). This will require urgent action given the rapid changes that are occurring in European dietary habits (Lindsay, 2003).

\section{An overview of the Mediterranean Diet}

The Mediterranean Diet has become a popular area of study due to observations made in 1960 of low incidences of chronic diseases and high life-expectancy rates attributed to the Crete population who consumed a traditional Mediterranean diet. Despite the high daily intakes of fat, epidemiological studies showed low prevalence of heart and other vascular diseases. (Seven countries study- a 25 year follow-up). Prevalence of cardiovascular disease varied from $2-10 \%$ in Southern European countries and from 10 to $18 \%$ in Northern European countries. Mortality rates varied greatly from East Finland $(262 / 1000)$ to Crete $(25 / 1000)$. Differences in mortality rates were attributed to nutritional habits, in particular to the intake of saturated fatty acids and flavonoids. Differences in types of fat emerged and the benefit of olive oil was evidenced by those studies (Tyrovolas \& Panagiotakos, 2010).

The original Mediterranean Diet was the diet of poor people where meat was a luxury and meals were based on raw vegetables, goat cheese, chicken rarely and red meat on festive days. The "Mediterranean Diet" gained much recognition and worldwide interest in the 1990s as a model for healthy eating habits. The diet is based on the traditional dietary patterns of Crete, a Greek island, and other parts of Greece and southern Italy. The diet is closely tied geographically to areas of olive oil cultivation in the Mediterranean Basin.

This diet was successfully resistant to the last 50 years of "modernizing" foods and drinks in industrialized countries. The "poor" diet of the people of the southern Mediterranean countries, consisting mainly of fruits and vegetables, beans and nuts, healthy grains, fish, olive oil, small amounts of dairy, and red wine, proved to be much more likely to lead to lifelong good health. The healthfulness of this pattern is corroborated by more than 50 years of epidemiological and experimental nutrition research.

Oldways, a USA non-profit organization, the Harvard School of Public Health, and the European Office of the World Health Organization (WHO) introduced the classic Mediterranean Diet in 1993 at a conference in Cambridge, USA, along with a Mediterranean Diet Pyramid graphic to represent it visually (http: //oldwayspt.org/resources/heritage-pyramids/ mediterranean-pyramid/overview, accessed on 31 March 2015).

In 1996 the Mediterranean Diet Foundation was created, with its headquarters in Catalonia, Spain and a scientific committee of 25 scientists from 11 Mediterranean and nonMediterranean countries (one from Netherlands) (http://dietamediterranea.com/en/foundation/ scientific-committee/, accessed on 31 March 2015).

During the $15^{\text {th }}$ Anniversary Mediterranean Diet Conference in November 2008, several major updates were made to the Classic Mediterranean Diet Pyramid by the Scientific Advisory Board. These changes focused on gathering plant foods (fruits, vegetables, grains, nuts, legumes, seeds, olives and olive oil) in a single group to visually emphasize their health benefits (http: //oldwayspt.org/resources/heritage-pyramids/ mediterranean-pyramid/overview, accessed 
on 31 March 2015). A new feature on the Mediterranean Diet Pyramid was the addition of herbs and spices, for reasons of both health and taste. Also, herbs and spices contribute to the national identities of various Mediterranean cuisines. The committee changed the placement of fish and shellfish on the pyramid, recognizing the benefits of eating fish and shellfish at least two times per week. Enjoy meals with others is now in the base of the Mediterranean Pyramid of 2008 launched in January 2009.

\section{Concluding remarks and further suggestions}

The objective of this paper was not to compare the Atlantic Diet with the Mediterranean Diet. More than 50 years of studies separate both concepts. As mentioned previously a wide variety of fish and shell fish is now placed in the updated Mediterranean Diet Pyramid with advice to eat fish and shellfish at least twice a week. There are no doubts that the residents of the Atlantic Diet region have traditionally a higher intake of fish and shellfish than the Mediterranean countries. Enjoy meals with others, recently placed in the base of the Mediterranean Diet Pyramid, is a common practice in Portugal and Galicia, where mealtimes are regarded as leisurely affairs to share with family and friends.

Diversity is also a key word. It is not only the type of food but also the frequency of their intake which makes a food component healthy or unhealthy. As mentioned before, no identification of bad or good food should be indicated to consumers in a regular balanced diet. A daily diet is not only food but also taste and pleasure. A combined balance of those elements, food and taste, is characteristic of the Atlantic Diet. Also, it is well known that food components interact, thus it is important to analyze a whole meal rather than the separate food components.

The Atlantic Diet is considered strategic by the Food-cluster Portugal Foods which has as major objectives: the surveillance and characterization of Atlantic Diet by identification, systematization and validation of products and recipes under the concept "Atlantic Diet - a Portuguese way of being". The continuing move from dietary tra- ditions which are local to diets that are global, as the Mediterranean Diet now is, requires high technological input and a science base, therefore companies and public and private $\mathrm{R} \& \mathrm{D}$ institutions must join together in efforts to validate and make global another regional healthy diet the Southern European Atlantic Diet or Atlantic Diet.

The previously reported epidemiological studies, showing higher adherence to the Atlantic Diet (Southern European Atlantic Diet) and its inverse association with the occurrence of non-fatal AMI and its association with a lower concentration of coronary disease markers, are a beginning for consolidation of the healthfulness of the Atlantic Diet pattern but more epidemiological and experimental nutrition research is needed to corroborate these findings.

\section{References}

Aguilera, C. M., Mesa, M. D., Ramirez-Tortosa, M. C., Quiles, J. L., \& Gil, A. (2003). Virgin olive and fish oils enhance the hepatic antioxidant defence system in atherosclerotic rabbits. Clinical Nutrition, 22(4), 379-384. doi:10 . 1016 / S0261 - 5614(03) 00038-4

Ames, B. N. \& Gold, L. S. (1998). The causes and prevention of cancer: the role of environment. Biotherapy, 11 (2-3), 205-220.

Araya, H. (1997). Produccion y manejo de datos de composicion quimica de alimentos en nutrición. In C. Moron, I. Zacarias, \& S. De Pablo (Eds.), (Chap. Use of food composition tables in food and nutrition interventions, pp. 9-19). FAO, Santiago (Chile). Oficina Regional para America Latina y el Caribe; Chile Univ., Santiago (Chile). Inst. de Nutricion y Tecnologia de los Alimentos.

Bertelli, A. A. E. (2007). Wine, research and cardiovascular disease: instructions for use. Atherosclerosis, 195(2), 242-247.

Block, G., Patterson, B., \& Subar, A. (1992). Fruit, vegetables, and cancer prevention: a review of the epidemiological evidence. $\mathrm{Nu}$ trition and Cancer, 18(1), 1-29.

Breslow, J. L. (2006). N-3 fatty acids and cardiovascular disease. American Journal of 
Clinical Nutrition, 83(6, S), 1477S-1482S. Symposium on n-3 Fatty Acids - Recommendations for Therapeutics and Prevention, Columbia Univ, Inst Human Nutr, New York, NY, MAY 21, 2005.

Dominguez-Perles, R., Mena, P., Garcia-Viguera, C., \& Moreno, D. A. (2014). Brassica foods as a dietary source of vitamin c: a review. Critical Reviews in Food Science and Nutrition, 54(8), 1076-1091. doi:10.1080/ 10408398.2011.626873

Fahey, J. W. \& Talalay, P. (1995). The role of crucifers in cancer chemoprotection (D. Gustine \& H. Flores, Eds.). Phytochemicals and health. American Society of Plant Physiologists. Rockville, Md.

FAOSTAT Food balances. (2011, 31 march 2015). Retrieved from http://faostat3.fao. org/download/FB/FBS/E

Gazeley, I. \& Newell, A. (2013). The first world war and working-class food consumption in britain. European Review of Economic History, 17(1), 71-94. doi:10.1093/ereh/ hes018

Gevers, E., Andrade, I., Hallikainen, A., Hedley, C., Holm, S., Laursen, P., ... Soerensen, H., et al. (1998). Eu-air, ct 94 2185: information on inherent food plant toxicants: nettox compilation of consumption data, report, 4: a resource generated by the euair nettox project (1995-1997). FD.

Gold, L., T.H., S., \& Ames, B. (1997). Prioritization of possible carcinogenic hazards in food. In D. R. T. Food Chemical Risk Analysis (Ed.), (pp. 267-295). New York: Chapman and Hall.

Goldman, I. L., Kopelberg, M., Debaene, J. E. P., \& Schwartz, B. S. (1996). Antiplatelet activity in onion (allium cepa) is sulfur dependent. Thrombosis and Haemostasis, $76(3), 450-452$.

Griffiths, G., Trueman, L., Crowther, T., Thomas, B., \& Smith, B. (2002). Onions - a global benefit to health. Phytotherapy Research, 16(7), 603-615. doi:10.1002/ptr. 1222

Guallar-Castillon, P., Oliveira, A., Lopes, C., Lopez-Garcia, E., \& Rodriguez-Artalejo, F. (2013). The southern european atlantic diet is associated with lower concentrations of markers of coronary risk. Atherosclerosis, 226(2), 502-509. doi:10 . 1016/ j . atherosclerosis.2012.11.035

Haber, B. (1997). The mediterranean diet: a view from history. The American journal of clinical nutrition, 66(4), 1053S-1057S.

He, K. (2009). Fish, long-chain omega-3 polyunsaturated fatty acids and prevention of cardiovascular disease-eat fish or take fish oil supplement? Progress in Cardiovascular Diseases, 52(2), 95-114. doi:10.1016/j. pcad.2009.06.003

Heinrich, M. \& Prieto, J. M. (2008). Diet and healthy ageing 2100: will we globalise local knowledge systems? Ageing Research Reviews, 7(3, SI), 249-274. doi:10.1016/j.arr. 2007.08.002

Jóhannesson, T. (2010). Agriculture in Iceland Conditions and Characteristics. ISBN: 978997988108. Published by The Agricultural University of Iceland.

Kull, I., Bergstrom, A., Lilja, G., Pershagen, G., \& Wickman, M. (2006). Fish consumption during the first year of life and development of allergic diseases during childhood. Allergy, 61 (8), 1009-1015. doi:10.1111/j. 1398-9995.2006.01115.x

Kumari, K., Mathew, B. C., \& Augusti, K. T. (1995). Antidiabetic and hypolipidemic effects of s-methyl cysteine sulfoxide isolated from allium-cepa linn. Indian Journal of Biochemistry \& Biophysics, 32(1), 49-54.

La Place, J. (2004). Meeting of the representatives of the Federation of European $\mathrm{Nu}$ trition Foundation. Book of Proceedings of the III Reunión Internacional la alimentación y la Nutrición en el siglo XXI: Dieta Atlántica, obesidad y la Nutrición en el Camino de Santiago, 19-23. Retrieved from http: / / www. fen.org. es / archivos / imgPublicaciones/15220071441.pdf

Leslie, J. (2000). Report of an initial study for the European Center of Atlantic Diet (CEDA) of Instituto Politécnico de Viana do Castelo (IPVC). developed by Jim Leslie Associates, UK. IPVC archive August 2000.

Lindsay, D. G. (2003). The atlantic diet and health: the priority research needs. In Proceedings of the $i$ international congress on 
the atlantic diet (pp. 17-19). Viana do Castelo, Portugal.

Negri, E., La Vecchia, C., Franceschi, S., D' Avanzo, B., \& Parazzini, F. (1991). Vegetable and fruit consumption and cancer risk. International Journal of Cancer, (48), 350-354.

Oliveira, A., Lopes, C., \& Rodriguez-Artalejo, F. (2010). Adherence to the southern european atlantic diet and occurrence of nonfatal acute myocardial infarction. American Journal of Clinical Nutrition, 92(1), 211217. doi:10.3945/ajcn.2009.29075

Rand, W. M., Windham, C. T., Wyse, B. W., \& Young, V. R. (1987). Food Composition Data: a User's Perspective. Food and $\mathrm{Nu}$ trition Bulletin. ISBN: 92-808-0633-5. Supplement (United Nations University), no. 12 / Tokyo (Japan), 226 p.

Renaud, S. \& Delorgeril, M. (1992). Wine, alcohol, platelets, and the french paradox for coronary heart-disease. Lancet, 339 (8808), 1523-1526. doi:10 . 1016/0140-6736(92) 91277-F

Rodrigues, A. S., Fogliano, V., Graziani, G., Mendes, S., Vale, A. P., \& Gonçalves, C. (2003). Nutritional value of onion regional varieties in northwest portugal. Electronic Journal of Environmental, Agricultural and Food Chemistry, 2(4), 519-524.

Smith, K. L. \& Guentzel, J. L. (2010). Mercury concentrations and omega- 3 fatty acids in fish and shrimp: preferential consumption for maximum health benefits. Marine Pollution Bulletin, 60(9), 1615-1618. doi:10 . 1016/j.marpolbul.2010.06.045

SPI. (2001, October). Strategic plan for Centro Europeu de Dieta Atlântica of Instituto Politécnico de Viana do Castelo developed by Sociedade Portuguesa de Inovação SA. Porto, Portugal.

Steinmetz, K. \& Potter, J. (1991). Vegetables, fruit, and cancer. II. Mechanisms. Cancer Causes Control, 2(6), 427-442.

Stene, L. C., Joner, G., \& Norwegian Childhood Diabet Study G. (2003). Use of cod liver oil during the first year of life is associated with lower risk of childhood-onset type 1 diabetes: a large, population-based, case- control study. American Journal of Clinical Nutrition, 78(6), 1128-1134.

Teyssier, C., Amiot, M. J., Mondy, N., Auger, J., Kahane, R., \& Siess, M. H. (2001). Effect of onion consumption by rats on hepatic drugmetabolizing enzymes. Food and Chemical Toxicology, 39(10), 981-987. doi:10.1016/ S0278-6915(01)00056-4

Tojo, R. (2008). Menús para comedores escolares de Galicia, generales y para necesidades nutricionales especificas. CD. Santiago de Compostela (Unidixital. Servicio de edición dixital da Universidad de Santiago de Compostela, Ed.).

Tojo, R. \& Leis, R. (2009). La Dieta Atlántica, el pescado y las algas - $\mathrm{Su}$ importancia en el neurodesarrollo y la función cerebral. In Fundación Dieta Atlántica and Universidade de Santiago de Compostela, Spain (Ed.), (Chap. El papel de la Dieta Atlántica como contrapunto saludable a la Dieta Ocidental actual, pp. 23-28). ISBN: 9788498870336.

Tyrovolas, S. \& Panagiotakos, D. B. (2010). The role of mediterranean type of diet on the development of cancer and cardiovascular disease, in the elderly: a systematic review. Maturitas, 65(2, SI), 122-130. doi:10.1016/ j.maturitas.2009.07.003

Van Horn, L., McCoin, M., Kris-Etherton, P. M., Burke, F., Carson, J. A. S., Champagne, C. M., ... Sikand, G. (2008). The evidence for dietary prevention and treatment of cardiovascular disease. Journal of the American Dietetic Association, 108(2), 287-331. doi:10.1016/j.jada.2007.10.050

Verhoeven, D. T. H., Godbohm, R. A., van Poppel, G., Verhagen, H., \& van den Brandt, P. A. (1996). Epidemiolgical studies on brassica vegetables and cancer risk. Cancer Epidemiology, Biomarkers \& Prevention, 5, 733-748.

Wang, C., Harris, W. S., Chung, M., Lichtenstein, A. H., Balk, E. M., Kupelnick, B., ... Lau, J. (2006). N-3 fatty acids from fish or fish-oil supplements, but not alphalinolenic acid, benefit cardiovascular disease outcomes in primary- and secondaryprevention studies: a systematic review. 
The Atlantic Diet | 119

American Journal of Clinical Nutrition,

84(1), $5-17$.

IJFS | April 2016 | Volume 5 | pages 106-119 